\title{
Angular spectrum approach for fast simulation of pulsed non-linear ultrasound fields
}

Du, Yigang; Jensen, Henrik; Jensen, Jørgen Arendt

Published in:

Proceedings of the 2011 IEEE International Ultrasonics Symposium

Link to article, DOI:

10.1109/ULTSYM.2011.0393

Publication date:

2011

Document Version

Early version, also known as pre-print

Link back to DTU Orbit

Citation (APA):

Du, Y., Jensen, H., \& Jensen, J. A. (2011). Angular spectrum approach for fast simulation of pulsed non-linear ultrasound fields. In Proceedings of the 2011 IEEE International Ultrasonics Symposium (pp. 1583-1586). IEEE. https://doi.org/10.1109/ULTSYM.2011.0393

\section{General rights}

Copyright and moral rights for the publications made accessible in the public portal are retained by the authors and/or other copyright owners and it is a condition of accessing publications that users recognise and abide by the legal requirements associated with these rights.

- Users may download and print one copy of any publication from the public portal for the purpose of private study or research.

- You may not further distribute the material or use it for any profit-making activity or commercial gain

- You may freely distribute the URL identifying the publication in the public portal

If you believe that this document breaches copyright please contact us providing details, and we will remove access to the work immediately and investigate your claim 
Paper presented at the IEEE International Ultrasonics Symposium, Orlando Florida, 2011:

\section{Angular spectrum approach for fast simulation of pulsed non-linear ultrasound fields}

Yigang D ${ }^{1,2}$, Henrik Jensen ${ }^{2}$ and J $\phi$ rgen Arendt Jensen ${ }^{1}$

${ }^{1}$ Center for Fast Ultrasound Imaging,

Biomedical Engineering group, Department of Electrical Engineering, Bldg. 349,

Technical University of Denmark, DK-2800 Kgs. Lyngby, Denmark

${ }^{2}$ BK Medical Aps, Mileparken 34, DK-2730 Herlev, Denmark,

To be published in Proceedings of IEEE International Ultrasonics Symposium, Orlando Florida, 2011. 


\title{
Angular spectrum approach for fast simulation of pulsed non-linear ultrasound fields
}

\author{
Yigang $\mathrm{Du}^{1,2}$, Henrik Jensen ${ }^{2}$ and Jørgen Arendt Jensen ${ }^{1}$ \\ 1) Center for Fast Ultrasound Imaging, Department of Electrical Engineering, Bldg. 349, \\ Technical University of Denmark, DK-2800 Kgs. Lyngby, Denmark. \\ 2) BK Medical Aps, Mileparken 34, DK-2730 Herlev, Denmark.
}

\begin{abstract}
The paper presents an Angular Spectrum Approach (ASA) for simulating pulsed non-linear ultrasound fields. The source of the ASA is generated by Field II, which can simulate array transducers of any arbitrary geometry and focusing. The non-linear ultrasound simulation program - Abersim, is used as the reference. A linear array transducer with 64 active elements is simulated by both Field II and Abersim. The excitation is a 2-cycle sine wave with a frequency of $5 \mathrm{MHz}$. The second harmonic field in the time domain is simulated using ASA. Pulse inversion is used in the Abersim simulation to remove the fundamental and keep the second harmonic field, since Abersim simulates non-linear fields with all harmonic components. ASA and Abersim are compared for the pulsed fundamental and second harmonic fields in the time domain at depths of $30 \mathrm{~mm}$, $40 \mathrm{~mm}$ (focal depth) and $60 \mathrm{~mm}$. Full widths at $-6 \mathrm{~dB}$ (FWHM) are $\{0.97,0.95\} \mathrm{mm}$ at the focal depth for the fundamental fields for ASA and Abersim, and $\{0.56,0.55\} \mathrm{mm}$ for the second harmonic fields. Full widths at $\mathbf{- 1 2} \mathrm{dB}$ are $\{1.27,1.26\} \mathrm{mm}$ for the fundamental fields for ASA and Abersim, and $\{0.77,0.73\}$ $\mathrm{mm}$ for the second harmonic fields. The calculation time, for the second harmonic fields, using ASA is 12 minutes and for all harmonic fields using Abersim is 14 hours. Compared to Abersim, the error of ASA for calculating the second harmonic fields is $1.5 \%$ at $-6 \mathrm{~dB}$ and $6.4 \%$ at $-12 \mathrm{~dB}$, and the calculation time is reduced by a factor of 70 .
\end{abstract}

\section{INTRODUCTION}

An efficient optimization of non-linear ultrasound imaging can be carried out using simulation programs, which should be fast and yield accurate results. Simulation of non-linear wave equation is usually solved by numerically integrating the KZK [1]-[4] or Burgers equation [5] based on the operator splitting method [6]. This makes the simulation slow and inefficient, since a small stepsize in the propagating direction has to be used each time in calculation of the forward nonlinear acoustic pressure. Thus, hundreds of steps are needed, if the desired simulated points are far from the original acoustic source.

Our previous studies [7], [8] presented an analytical solution to the non-linear Westervelt equation [9], where an Angular Spectrum Approach (ASA) has been used to solve it in one iteration step. This makes the simulation of non-linear ultrasound fields hundreds of times faster than using numerical solutions. The previous studies focused on simulating the monochromatic field. However, in an ultrasound imaging system, a short pulse is usually emitted from the transducer. This yields a high bandwidth signal, and calculation with a single temporal frequency is insufficient. The purpose of this paper is to develop the ASA for simulating pulsed non-linear ultrasound fields. The source for the ASA will be created by Field II [10], [11] that can simulate array transducers of any arbitrary geometry, focusing, and excitation. A released nonlinear ultrasound simulation program - Abersim [12], [13] is used as the reference to validate the accuracy of ASA.

The solution for the pulsed non-linear ultrasound field is given and the implementation is described in Section II. The simulated results using both ASA and Abersim are illustrated in Section III.

\section{METHOD}

A solution to the Westervelt equation for monochromatic fields using the ASA can be expressed by [14], [15]

$$
\begin{aligned}
\hat{P}_{2}\left(k_{x}, k_{y}, z_{1}\right)= & \frac{\beta k^{2}}{2 \pi^{2} \rho_{0} c_{0}^{2}} \iint \frac{\hat{P}_{0}\left(k_{x}^{\prime}, k_{y}^{\prime}, z_{0}\right)}{k_{z 2}^{2}-\left(k_{z}^{\prime}+k_{z}^{\prime \prime}\right)^{2}} \\
& \times\left[e^{-j\left(z_{1}-z_{0}\right)\left(k_{z}^{\prime}+k_{z}^{\prime \prime}\right)}-e^{-j\left(z_{1}-z_{0}\right) k_{z 2}}\right] \\
& \times \hat{P}_{0}\left(k_{x}-k_{x}^{\prime}, k_{y}-k_{y}^{\prime}, z_{0}\right) d k_{x}^{\prime} d k_{y}^{\prime},
\end{aligned}
$$

where

$$
\begin{aligned}
k_{z 2} & =\sqrt{4 k^{2}-k_{x}^{2}-k_{y}^{2}} \\
k_{z}^{\prime} & =\sqrt{k^{2}-\left(k_{x}^{\prime}\right)^{2}-\left(k_{y}^{\prime}\right)^{2}} \\
k_{z}^{\prime \prime} & =\sqrt{k^{2}-\left(k_{x}-k_{x}^{\prime}\right)^{2}-\left(k_{y}-k_{y}^{\prime}\right)^{2}} .
\end{aligned}
$$

$\hat{P}_{0}$ and $\hat{P}_{2}$ are the pressures of the source and second harmonic components in $k$-space. $c_{0}$ is sound speed, $\rho_{0}$ is medium density, $\beta$ is the coefficient of nonlinearity, and $k$ is the wave number. $k_{x}$ and $k_{y}$ are wave numbers along the $x$-axis and $y$-axis as shown in Fig. 1, which also shows the acoustic propagation and calculation of the second harmonic fields $p_{2}$ using the ASA. The first plane at $z=z_{0}$ is the source, which is close to the transducer surface and, thus, non-linear effect at $z=z_{0}$ can be neglected. The source plane is calculated using Field II. The second harmonic component at $z=z_{1}$ is then obtained after propagation using the ASA as formulated in (1). 


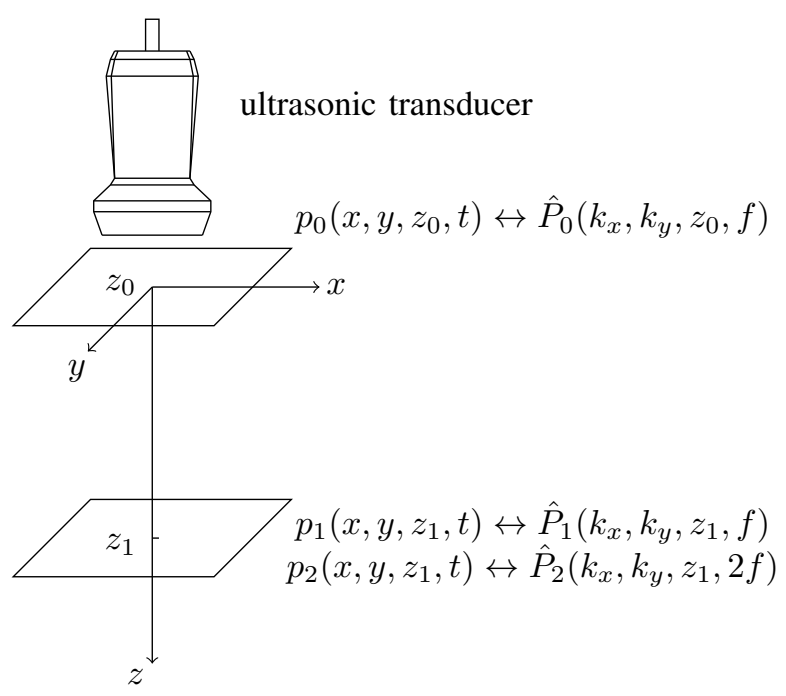

Fig. 1: Schematic view of the acoustic propagation using ASA - The planes are parallel to the transducer surface. Source plane at $z=z_{0}$; Simulated plane at $z=z_{1}$.

The previous solution using (1) is for simulating monochromatic fields. To expand it to a high bandwidth ultrasound field, each temporal frequency component is supposed to be calculated individually. In this case, (1) can be transferred and given by

$$
\begin{aligned}
\hat{P}_{2}\left(k_{x}, k_{y}, z_{1}, 2 f\right)= & \frac{2 \beta f^{2}}{\rho_{0} c_{0}^{4}} \iint \frac{\hat{P}_{0}\left(k_{x}-k_{x}^{\prime}, k_{y}-k_{y}^{\prime}, z_{0}, f\right)}{k_{z 2}^{2}-\left(k_{z}^{\prime}+k_{z}^{\prime \prime}\right)^{2}} \\
& \times\left[e^{-j\left(z_{1}-z_{0}\right)\left(k_{z}^{\prime}+k_{z}^{\prime \prime}\right)}-e^{-j\left(z_{1}-z_{0}\right) k_{z 2}}\right] \\
& \times \hat{P}_{0}\left(k_{x}^{\prime}, k_{y}^{\prime}, z_{0}, f\right) d k_{x}^{\prime} d k_{y}^{\prime},
\end{aligned}
$$

where $f$ is the temporal frequency variable. $\hat{P}_{0}\left(k_{x}, k_{y}, z_{0}, f\right)$ is the Fourier transform of $p_{0}\left(x, y, z_{0}, t\right)$ that is the pressure for the ASA source in time domain and calculated by Field II using the function "calc_hp" [16]. A linear array transducer is configured by Field II using the function "xdc_focused_array". The transducer parameters, and impulse and frequency responses used in the simulation are shown in Table I and Fig. 2, respectively. These data refer to a commercially available linear array transducer. The size of a kerf for the transducer is too small and not specified by Abersim. To match it, the kerf is set to zero in Field II. The fundamental and second harmonic components are obtained using the ASA by implementing (2) as shown in Fig. 1, where the bandwidth of the second harmonic components are twice of the fundamental one. The time domain pressure $p_{1}$ and $p_{2}$ at the simulated plane are calculated using a 3D (2D for space and 1D for time) inverse Fourier transform.

The transducer with the same setup as shown in Table I is also simulated in Abersim [17], [18] as a reference. A pulse inversion method [19], [20] is used to remove the fundamental component. This will be made by sending two inverted excitations in turn and adding the reflected simulated signals resulting in the cancelation of odd harmonic components. Then a bandpass filter is applied to remove the 4th and higher even harmonic components.
TABLE I: Parameters of the transducer

\begin{tabular}{l||c|c} 
Center frequency $f_{0}$ & $7 \mathrm{MHz}$ & $60 \%$ \\
Bandwidth bw & $100 \mathrm{MHz}$ & \\
Sampling frequency $f_{s}$ & 2-cycle sine wave & $5 \mathrm{MHz}$ \\
Excitation & $40 \mathrm{~mm}$ & \\
Excitation's frequency & $20 \mathrm{~mm}$ & 64 \\
Electronic focus & $0.208 \mathrm{~mm}$ & \\
Elevation focus & $4.5 \mathrm{~mm}$ & \\
Number of elements &
\end{tabular}
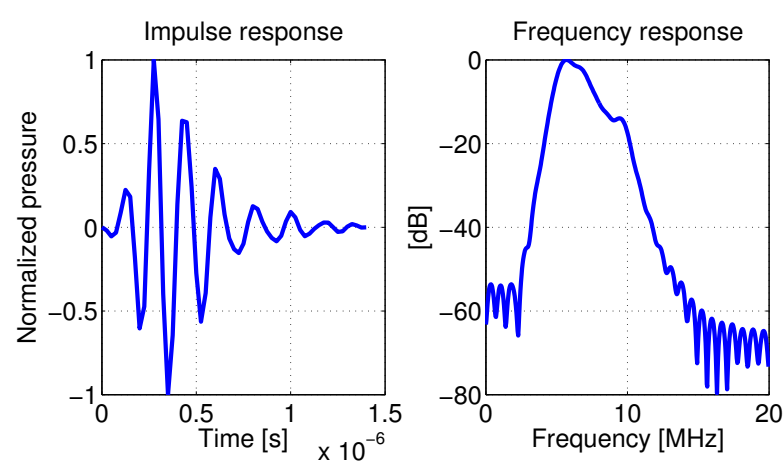

Fig. 2: Impulse and frequency responses of the simulated transducer

\section{RESUlts}

The emitted pressure fields are calculated by the ASA and Abersim. Fig. 3 presents the fundamental and second harmonic fields in the time domain at the focal depth $40 \mathrm{~mm}$ from the transducer surface. A visibly good agreement can be found from the comparison of the results. The calculation time, for Abersim, which can simulate all harmonic fields, is 14 hours, and for ASA, it is 12 minutes for simulating the second harmonic fields. The simulations are made by Matlab 7.11.0 (R2010b) using a computer with $2.4 \mathrm{GHz}$ Q6600 CPU and 4 GB memory. To further investigate the ASA results, the fundamental and second harmonic fields at different depths are calculated by ASA and Abersim as shown in Figs. 4 and 5. The full widths at $-6 \mathrm{~dB}$ and $-12 \mathrm{~dB}$ of the results using different

\begin{tabular}{|c|c|c|c|c|}
\hline \multicolumn{2}{|c|}{ Depth $=30 \mathrm{~mm}$} & ASA & Abersim & Error \\
\hline \multirow{2}{*}{ Fundamental } & FW at $-6 \mathrm{~dB}$ & $2.97 \mathrm{~mm}$ & $2.98 \mathrm{~mm}$ & $0.6 \%$ \\
\hline & FW at $-12 \mathrm{~dB}$ & $4.40 \mathrm{~mm}$ & $4.41 \mathrm{~mm}$ & $0.2 \%$ \\
\hline \multirow{2}{*}{ 2nd harmonic } & FW at $-6 \mathrm{~dB}$ & $2.56 \mathrm{~mm}$ & $2.62 \mathrm{~mm}$ & $2.5 \%$ \\
\hline & FW at $-12 \mathrm{~dB}$ & $3.37 \mathrm{~mm}$ & $3.45 \mathrm{~mm}$ & $2.4 \%$ \\
\hline \multicolumn{2}{|c|}{ Depth $=40 \mathrm{~mm}$} & ASA & Abersim & Error \\
\hline \multirow{2}{*}{ Fundamental } & FW at $-6 \mathrm{~dB}$ & $0.97 \mathrm{~mm}$ & $0.95 \mathrm{~mm}$ & $1.7 \%$ \\
\hline & $\mathrm{FW}$ at $-12 \mathrm{~dB}$ & $1.27 \mathrm{~mm}$ & $1.26 \mathrm{~mm}$ & $1.2 \%$ \\
\hline \multirow{2}{*}{ 2nd harmonic } & $\mathrm{FW}$ at $-6 \mathrm{~dB}$ & $0.56 \mathrm{~mm}$ & $0.55 \mathrm{~mm}$ & $1.5 \%$ \\
\hline & $\mathrm{FW}$ at $-12 \mathrm{~dB}$ & $0.77 \mathrm{~mm}$ & $0.73 \mathrm{~mm}$ & $6.4 \%$ \\
\hline \multicolumn{2}{|c|}{ Depth $=60 \mathrm{~mm}$} & ASA & Abersim & Error \\
\hline \multirow{2}{*}{ Fundamental } & FW at $-6 \mathrm{~dB}$ & $6.06 \mathrm{~mm}$ & $5.99 \mathrm{~mm}$ & $1.1 \%$ \\
\hline & $\mathrm{FW}$ at $-12 \mathrm{~dB}$ & $8.90 \mathrm{~mm}$ & $8.82 \mathrm{~mm}$ & $1.0 \%$ \\
\hline \multirow{2}{*}{ 2nd harmonic } & FW at $-6 \mathrm{~dB}$ & $5.29 \mathrm{~mm}$ & $5.21 \mathrm{~mm}$ & $1.4 \%$ \\
\hline & $\mathrm{FW}$ at $-12 \mathrm{~dB}$ & $7.01 \mathrm{~mm}$ & $6.89 \mathrm{~mm}$ & $1.6 \%$ \\
\hline
\end{tabular}
methods are compared and shown in Table II.

TABLE II: Comparison of the full width (FW) 

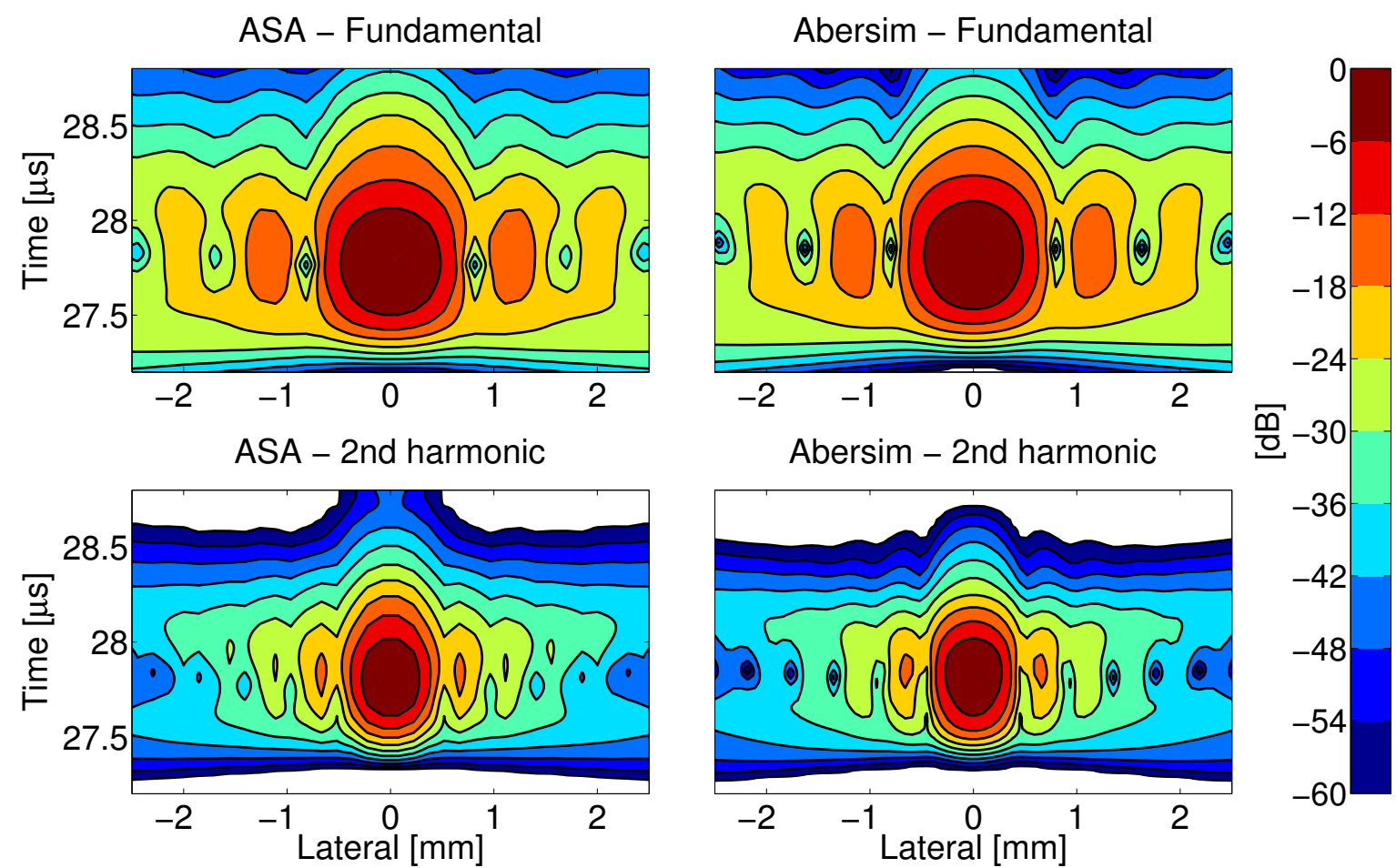

Fig. 3: Emitted ultrasound fields calculated by ASA and Abersim - Fundamental and second harmonic fields at the focal depth (40 mm) are shown in the figure with $6 \mathrm{~dB}$ between two adjacent color lines.
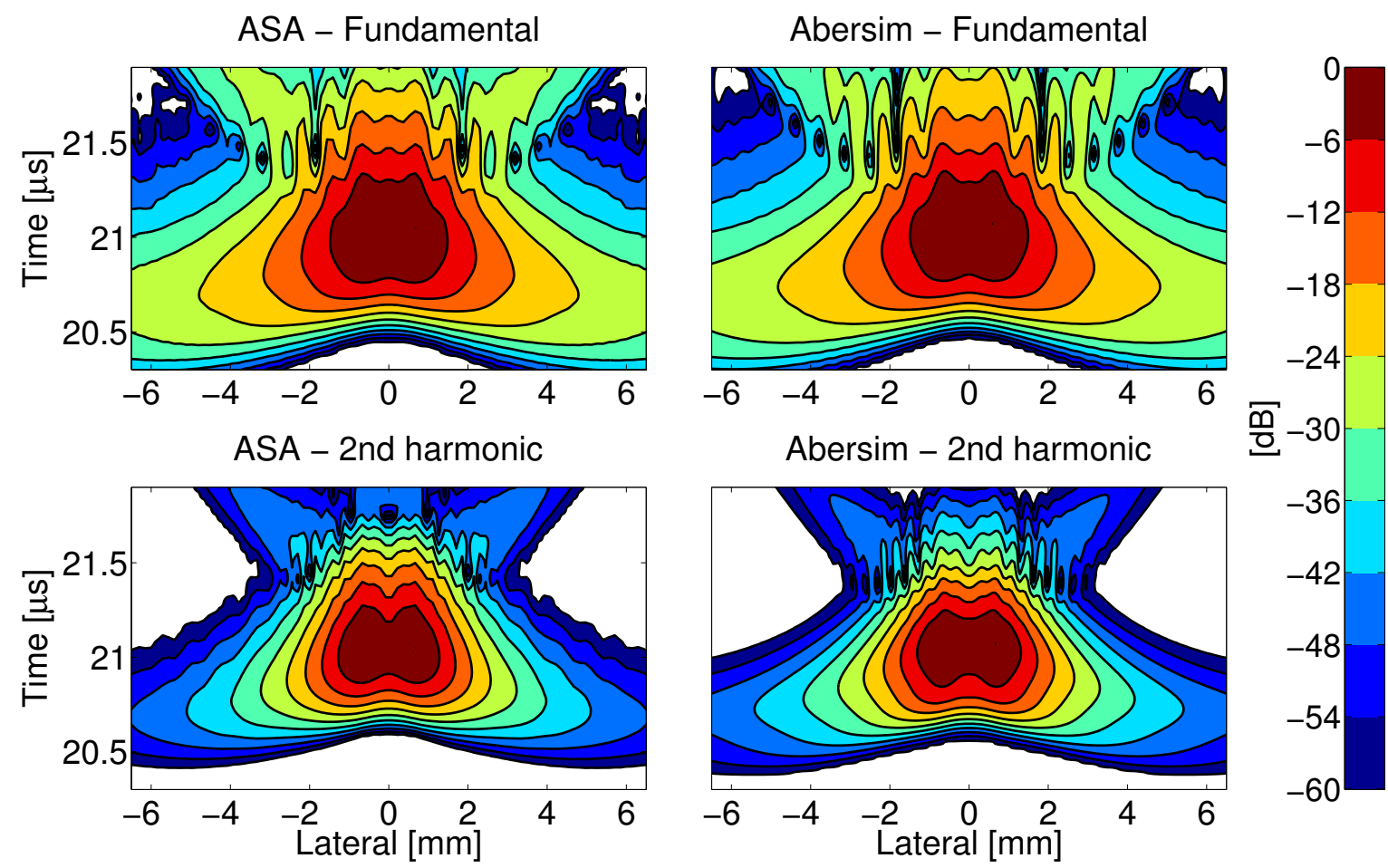

Fig. 4: Emitted fields calculated by ASA and Abersim - Fundamental and second harmonic fields are at $30 \mathrm{~mm}$ from the transducer. 

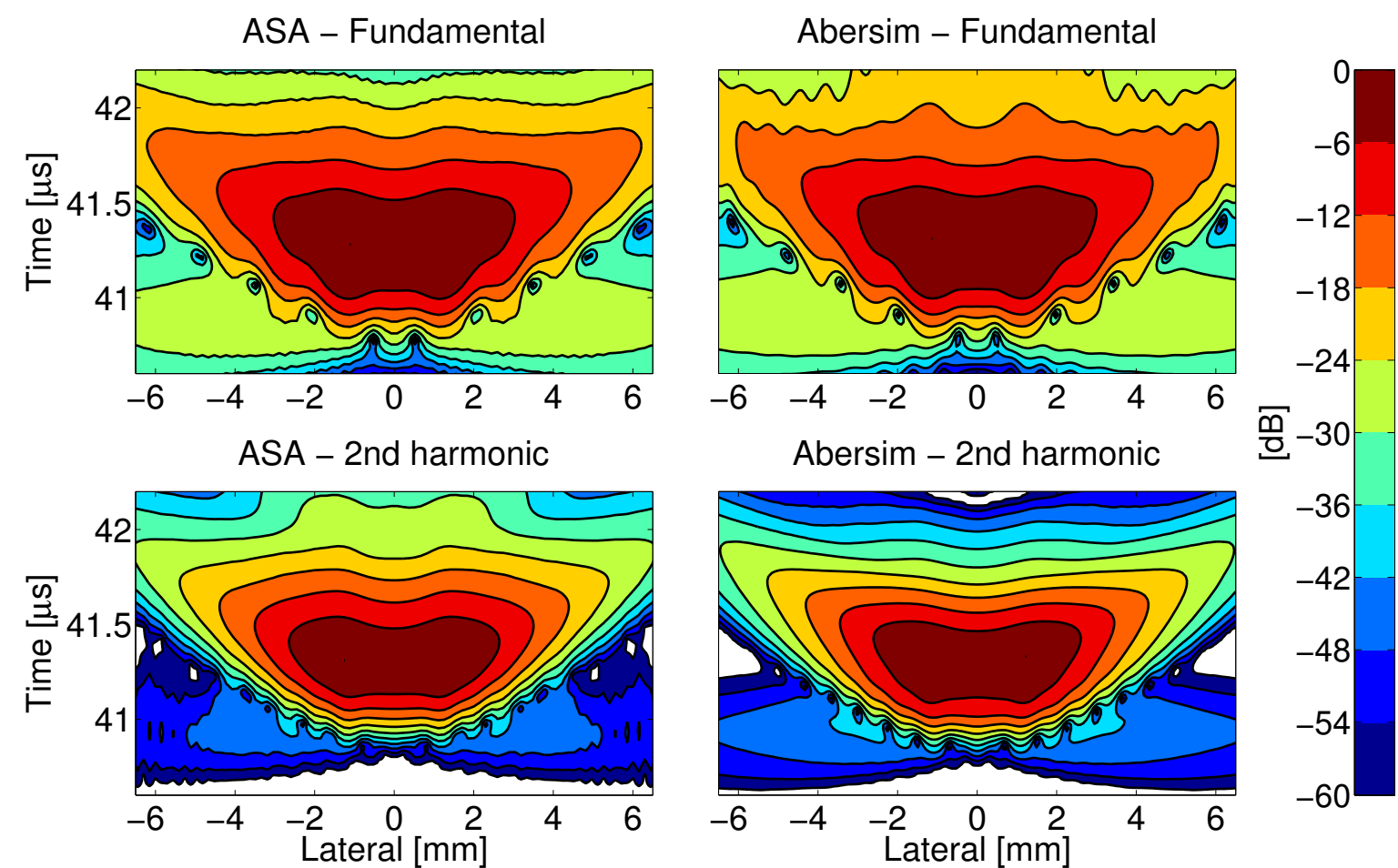

Fig. 5: Emitted fields calculated by ASA and Abersim - Fundamental and second harmonic fields are at $60 \mathrm{~mm}$ from the transducer.

\section{CONCLUSION}

The pulsed non-linear ultrasound fields are successfully simulated by the ASA, whose accuracy is investigated and compared to Abersim. The ASA using the source generated by Field II, makes the non-linear ultrasound simulation flexible to any kind of transducer with arbitrary focus and excitation. The calculation speed using the ASA is 70 times faster than using Abersim for simulating the second harmonic fields.

\section{ACKNOWLEDGMENT}

This work was supported by grant 08-032480 from the Danish Agency for Science, Technology and Innovation, and by BK Medical Aps, Denmark.

\section{REFERENCES}

[1] R. J. Zemp, J. Tavakkoli, and R.S. C. Cobbold. Modeling of nonlinear ultrasound propagation in tissue from array transducers. J. Acoust. Soc. Am., 113(1):139-152, 2003.

[2] E. A. Zabolotskaya and R. V. Khokhlov. Quasi-plane waves in the nonlinear acoustics of confined beams. Sov. Phys. Acoust., 15:35-40, 1969.

[3] Y. Lee. Numerical solution of the $K Z K$ equation for pulsed finite amplitude sound beams in thermoviscous fluids. $\mathrm{PhD}$ thesis, The University of Texas at Austin, 1993.

[4] V. P. Kuznetsov. Equations of nonlinear Acoustics. Sov. Phys. Acoust., $16: 467-470,1971$

[5] J. M. Burgers. A mathematical model illustrating the theory of turbulence. In R. von Mises and T. von Kármán, editors, Advances in Applied Mechanics, volume 1, pages 171-199. Academic Press, 1948.

[6] T. Nouri-Baranger, E. Closset, and D. Cathignol. Numerical solution for nonlinear acoustic beam radiated from non axisymmetric plane transducers using the operator splitting method. In Proc. IEEE Ultrason. Symp., pages 479-482, 2001.

[7] Y. Du, H. Jensen, and J. A. Jensen. Simulation of second harmonic ultrasound fields. In Proc. IEEE Ultrason. Symp., pages 2191-2194, 2010 .
[8] Y. Du, H. Jensen, and J. A. Jensen. Comparison of simulated and measured non-linear ultrasound fields. In Med. Imag. V Symp., volume 79680P, pages 1-10, 2011.

[9] P. J. Westervelt. Parametric acoustic array. J. Acoust. Soc. Am., 35:535537, 1963.

[10] J. A. Jensen and N. B. Svendsen. Calculation of pressure fields from arbitrarily shaped, apodized, and excited ultrasound transducers. IEEE Trans. Ultrason., Ferroelec., Freq. Contr., 39:262-267, 1992.

[11] J. A. Jensen. Field: A program for simulating ultrasound systems. In Med. Biol. Eng. Comp., volume 34, pages 351-353, 1996.

[12] T. Varslot and G. Taraldsen. Computer simulation of forward wave propagation in soft tissue. IEEE Trans. Ultrason., Ferroelec., Freq. Contr., 52(9):1473-1482, 2005.

[13] T. Varslot and S. E. Måsøy. Forward propagation of acoustic pressure pulses in 3D soft biological tissue, Modeling, Identification and Control. IEEE Trans. Ultrason., Ferroelec., Freq. Contr., 27(3):181-200, 2006.

[14] B. J. Landsberger and M. F. Hamilton. Second-hamonic generation in sound beams reflected from, and transmitted through, immersed elastic solids. J. Acoust. Soc. Am., 109(2):488-500, 2001.

[15] Y. Xiang. Statistical Model of Beam Distortion by Tissue Inhomogeneities in Tissue Harmonic Imaging. PhD thesis, The University of Texas at Austin, December 2004.

[16] J. A. Jensen. User guide for the Field II program. Technical report, Technical University of Denmark, Lyngby, Denmark, 2001.

[17] M. E. Frijlink, H. Kaupang, T. Varslot, and S.-E. Måsøy. Abersim: a simulation program for 3D nonlinear acoustic wave propagation for arbitrary pulses and arbitrary transducer geometries. In Proc. IEEE Ultrason. Symp., pages 1282-1285, 2008.

[18] H. Kaupang. Abersim 2.x Reference manual with tutorials. Norwegian University of Science and Technology, 2008.

[19] C. S. Chapman and J. C. Lazenby. Ultrasound imaging system employing phase inversion subtraction to enhance the image. US Patent, 5632277, 1997.

[20] D. H. Simpson, C. T. Chin, and P. N. Burns. Pulse inversion Doppler: a new method for detecting nonlinear echoes from microbubble contrast agents. IEEE Trans. Ultrason., Ferroelec., Freq. Contr., 46(2):372-382, 1999. 